\title{
Avaliação do Impacto de Motoristas Mal Comportados no Congestionamento em Rodovias
}

\author{
Luiz F. Giserman, Thales T. Almeida e Luís Henrique M. K. Costa \\ ${ }^{1}$ Grupo de Teleinformática e Automação (GTA) \\ PEE/COPPE-DEL/Poli \\ Universidade Federal do Rio de Janeiro (UFRJ)
}

\begin{abstract}
Resumo. O caminho para um trânsito mais eficiente e inteligente é de suma importância para a população mundial. O transporte diário é uma constante na vida das pessoas e o seu funcionamento afeta diretamente a qualidade de vida delas. Os engarrafamentos causam perdas econômicas e afetam o meio ambiente. Por outro lado, para além da relação entre a capacidade das vias e a quantidade de automóveis nas mesmas, o comportamento do motorista influencia a formação e o tempo de duração dos congestionamentos. Neste contexto, este artigo propõe revisar ações de condutores que sejam prejudiciais ao trânsito e analisa uma delas a partir de simulações de mobilidade urbana, com dados sintéticos e reais, utilizando o SUMO. Os resultados mostram que a ação estudada tem um impacto significativo no trânsito e no meio ambiente. $\mathrm{Na}$ simulação real, o tempo perdido no trânsito quando motoristas praticam a ação estudada e a emissão de $\mathrm{CO}_{2}$ mostraram-se 25 e 2,6 vezes maiores do que na situação de trânsito livre, respectivamente. Concluindo, o artigo avalia soluções tecnológicas além das convencionais visando evitar a prática dessas ações por parte de motoristas no cotidiano e mitigar seus efeitos.
\end{abstract}

\begin{abstract}
The path to more efficient and intelligent traffic patterns is of high importance to the worldwide population. Transportation is a daily constant on people's lives and its flow directly affects their life quality. Congestion is responsible for economic loss and environmental issues. Other than the relationship between road capacities and the quantity of vehicles in them, the driver's behavior influences the formation and duration of congestions. Within this context, this article proposes analysing driver's actions that are negative toward the flow of traffic and studies one of them by urban mobility simulations using sinthetic and real world data along with Simulation of Urban Mobility (SUMO). The simulation with real data shows that the time loss in traffic and the emission of $\mathrm{CO}_{2}$ when drivers undergo the studied action can be, respectively, 25 and 2,6 times bigger than when they don't. This article then proposes a study of technologies and ideas to avoid the daily practices of those actions by drivers and to mitigate their effects.
\end{abstract}

\section{Introdução}

O tempo gasto no trajeto para o trabalho, assim como os engarrafamentos, causam perdas econômicas e afetam a saúde das pessoas. É de interesse, portanto, estudar como amenizar o congestionamento nas vias. Para isso, é fundamental entender as variáveis responsáveis pelo engarrafamento, como frenagem, distância entre carros e o comportamento 
humano [Chaurasia e Verma, 2009]. Este último se reflete nas outras variáveis, já que o tempo de reação e a tomada de decisão de cada motorista é diferente. As imperfeições do ser humano no trânsito podem resultar em ações negativas ao tráfego [Malta et al., 2009]. Neste artigo, o conceito de ação negativa ao trânsito é apresentado, com destaque para a invasão do acostamento. Isto acontece quando um motorista, face a um congestionamento em uma rodovia, emprega a faixa de acostamento como se esta fosse uma faixa de rolamento regular, a fim de ganhar vantagem "ultrapassando" parte do trânsito engarrafado.

A invasão do acostamento em situações de congestionamento é frequente, em maior ou menor grau, nas rodovias brasileiras - apesar de constituir uma infração de trânsito. Do ponto de vista da utilização da rodovia, essa ação é equivalente a um afunilamento de uma via, e desta forma ela é modelada no presente trabalho. Assim, o objetivo deste trabalho é quantificar o impacto desta ação negativa dos motoristas no agravamento do congestionamento. É intuitivo que esta atitude, ao aumentar o afunilamento, aumenta o tempo gasto no trânsito pelos motoristas que se comportam bem. A partir da modelagem desta situação em um simulador de mobilidade veicular, analisa-se o aumento deste tempo em função da proporção de motoristas dispostos a infringir a lei.

Com simulações utilizando vias sintéticas e reais, a partir do simulador de mobilidade urbana, SUMO (Simulator of Urban Mobility) [Lopez et al., 2018], foi possível comprovar a negatividade dessa ação ao congestionamento e ao meio ambiente, com resultados significativos. Com $15 \%$ de infratores, na simulação sintética, há um aumento de $(60 \pm 1,2) \%$ de tempo perdido no trânsito em uma das vias e $(26 \pm 0,8) \%$ de emissão de $\mathrm{CO}_{2}$. Na simulação real, o tempo perdido no trânsito quando motoristas praticam essa ação e a emissão de $\mathrm{CO}_{2}$ mostraram-se 25 e 2,6 vezes maiores do que na situação de trânsito livre, respectivamente.

Existem muitas maneiras de mitigar ou prevenir ações negativas. Dentre elas, no caso do afunilamento das vias, a execução de algoritmos de mesclagem de faixas. Esses algoritmos contam com a comunicação entre veículos com a finalidade de coordenar as velocidades, espaços entre os carros e a vez de cada condutor em uma mesclagem. O conceito de redes veiculares ad-hoc, ou VANETs (Vehicular Ad-Hoc Networks) estabelece a comunicação entre veículos e possibilita a execução desses algoritmos de forma inteligente. Este artigo, depois de comprovar a negatividade da invasão ao acostamento e desenvolver o conceito de VANETs, caracteriza um algoritmo de mesclagem, o Zíper, e aponta mecanismos de incentivo/penalidade que podem ser aplicados a motoristas que vierem a praticar ações negativas ao trânsito, utilizando redes veiculares ou não.

Este artigo está organizado da seguinte forma. A Seção 2 apresenta os trabalhos relacionados. A Seção 3 conceitua as ações negativas e apresenta o objeto de estudo. A Seção 4 descreve as tecnologias, bem como as simulações de vias sintéticas e seus resultados. Já a Seção 5 apresenta as tecnologias, os dados e as simulações de vias reais, além dos resultados destas simulações. A Seção 6 conceitua a comunicação entre veículos e estuda os mecanismos de mitigação/prevenção do objeto de estudo, e de outras ações negativas ao trânsito. Por fim, a Seção 7 conclui o artigo e indica trabalhos futuros.

\section{Trabalhos Relacionados}

O presente trabalho aborda o comportamento do motorista no trânsito, a prevenção de congestionamentos e as soluções relacionadas de redes veiculares. Estes são os tópicos 
cobertos pelos trabalhos relacionados descritos nesta seção.

[Chaurasia e Verma, 2009] descrevem o comportamento dos motoristas no trânsito, dividindo-os em categorias diferentes: normal, tímido e agressivo. Um motorista tímido pode encarar congestionamentos, sinais vermelhos e veículos lentos em sua frente. Com a sua dificuldade em mudar de faixa, seu tempo estimado de viagem pode ser maior. Para manter o tempo estimado, o motorista pode mudar o comportamento de tímido para agressivo, configurando uma nova categoria de comportamento: o apressado. [Chaurasia e Verma, 2009] também propõem a comunicação entre veículos para a troca de mensagens de aviso entre eles, como neste artigo, e analisa os efeitos mitigatórios dessas mensagens por meio de simulações com os motoristas apressados, com a finalidade de evitar colisões, o que se difere desse artigo, que se preocupa em evitar infrações ou ações negativas ao congestionamento.

[Malta et al., 2009] analisam o comportamento de motoristas em possíveis situações perigosas. A análise se baseia em 373 motoristas conduzindo carros em rodovias no Japão, por meio de gravações de voz e de vídeo, e considera a expressão por voz e a força de acionamento do freio para identificar as situações de risco. Destacou-se uma relação entre as áreas onde ocorreram possíveis situações de risco e as áreas de forte frenagem. Esse trabalho contribui para este artigo por relacionar o comportamento de motoristas à frenagem em situações de risco, normalmente geradas por ações negativas.

[Bevly et al., 2016] analisam o estado da arte de mecanismos de mudança e de mesclagem de faixas para veículos conectados e automatizados. Para isso, considerando o conceito de redes veiculares, os autores abordam tecnologias diferentes de geolocalização de veículos, discutem o tipo de mensagem a serem trocadas entre os veículos e a capacidade necessária da rede para a prática desses mecanismos. Depois, comentam sobre propostas e testes de algoritmos de mudança e de mesclagem de faixas. Ainda sobre essa classe de algoritmos, [Baselt et al., 2014] definem uma medida para quantificar a justiça de um algoritmo desse tipo, no sentido de beneficiar todos os condutores de forma igualitária. [Wang et al., 2009] analisam a acurácia de sensores de distância dos carros e propõe algoritmos de mesclagem baseados nestas medidas de distância, considerando limites de segurança. Esses artigos, por proporem algoritmos de mesclagem de faixas e por os simularem em sistemas de redes veiculares, contribuem para a mitigação do problema da invasão ao acostamento, que pode ser reduzido a um afunilamento de faixas.

[Chacon e Kornhauser, 2012] propõem modificar o comportamento de motoristas com uma tecnologia de Cruise Control inteligente que obriga uma separação mínima entre veículos a partir de sensores de distância. É realizada uma comparação entre veículos com e sem a tecnologia, por meio da simulação de uma rodovia de Los Angeles. Os resultados mostram que esse espaço mínimo obrigatório promove um trânsito mais fluido, reduzindo a frequência de afunilamentos. A diferença do presente trabalho para esse artigo é avaliar o conceito de ação negativa ao trânsito, a análise de um comportamento específico dos condutores e o estudo de mitigação e de prevenção dessas ações.

Outros trabalhos avaliam ou propõem sistemas de incentivo/penalidade para melhorar a fluidez do trânsito. [Abbas et al., 2019] propõe multas automáticas com o auxílio de redes veiculares. Já [Merugu et al., 2009] propõe incentivos para os motoristas que praticarem boas ações no trânsito, como se deslocar fora dos horários de pico. 
[Chang et al., 2015] propõe um sistema no qual condutores podem reportar infração de outros motoristas. [Pinquet et al., 2011] medem a eficácia de multas na província de Quebec, no Canadá, frente à possibilidade de um condutor perder a sua licença caso acumule muitas infrações.

A contribuição científica do presente trabalho é estabelecer o conceito de ações negativas ao trânsito, analisar um comportamento negativo do condutor ao trânsito - a invasão do acostamento - e, consequentemente, o problema relacionado ao afunilamento de vias. Por fim, este trabalho estuda mecanismos para mitigar e prevenir essa e outras ações prejudiciais ao trânsito, considerando o conceito de redes veiculares.

\section{Ações Negativas}

O tráfego de veículos em uma rodovia suficientemente longa e sem sinais de trânsito, na qual os veículos mantêm velocidade constante e espaçamento fixo entre si seria, hipoteticamente, livre de congestionamento. Na vida real, esta situação inexiste. A frenagem de um condutor provoca a diminuição do espaço entre o seu veículo e o veículo que o sucede. Essa diminuição da distância leva à frenagem do motorista seguinte, e assim por diante, como efeito da frenagem se propagando ao longo do tráfego local.

A frenagem inoportuna, ou com intensidade desnecessária, é inevitável em carros dirigidos por seres humanos. Isso porque o tempo de reação de cada condutor não é o mesmo [Chaurasia e Verma, 2009] e, além disso, o ser humano não consegue calcular as distâncias e velocidades apropriadas a olho nu, ocasionando o acionamento do freio em instantes que frequentemente não são ideais. Muitos eventos que são comuns no trânsito podem resultar em uma frenagem desnecessária: uma simples mudança de faixa pode ser responsável pela frenagem dos motoristas da faixa de destino; dirigir em alta velocidade em uma via não vazia, pois resulta na diminuição de velocidade quando o condutor se aproxima repentinamente de outro veículo à sua frente.

O comportamento do motorista influencia o número de ações negativas praticadas. Por exemplo, [Chaurasia e Verma, 2009] definem o tipo de comportamento apressado pela condição de impaciência do motorista, que torna a sua direção mais agressiva. Esta produz velocidades maiores, espaços menores entre os carros, acelerações e frenagens bruscas, e maiores chances de decisões equivocadas. [Malta et al., 2009] estudam o comportamento de diferentes motoristas para identificar ações e momentos de risco de condução. Em 17 das 25 situações de risco, houve forte frenagem por parte do condutor. Uma vez conhecidas as ações negativas ao trânsito, é possível mitigá-las ou preveni-las.

\subsection{A Ação Negativa Estudada}

Uma ação que, de acordo com os problemas de frenagem, parece intuitivamente prejudicial ao trânsito é a invasão do acostamento por parte do condutor, em situações de congestionamento em rodovias. Isso porque o acostamento, quando termina, força o condutor a voltar para as faixas regulares, o que provoca uma frenagem por parte dos motoristas dessas faixas de modo a liberar espaço para o motorista infrator. A diferença dessa mudança de faixa para uma mudança comum é que a faixa do acostamento, em muitos momentos, deixa de existir, fazendo com que o motorista freie até ficar com uma velocidade próxima ou igual a zero se não efetuar a mudança antes de seu término. Nesse caso, a velocidade do condutor assim que voltar à faixa regular ainda será, na maioria 
dos casos, inferior à dos motoristas que transitavam por ali, ocasionando uma frenagem brusca por parte deles.

Essa situação é análoga a um afunilamento, no qual uma via com um certo número de faixas passa a ter menos faixas, forçando a migração dos condutores das faixas exteriores para as mais centrais (como na Figura 1), ou mesmo, análoga a uma faixa obstruída, já que, nesse caso, existe um limite para a mudança de faixas. Nesse caso, a diferença, quando motoristas utilizam o acostamento, é que aumenta a proporção do afunilamento: em vez de um funil de duas para uma faixa, tem-se um funil de três para uma faixa.

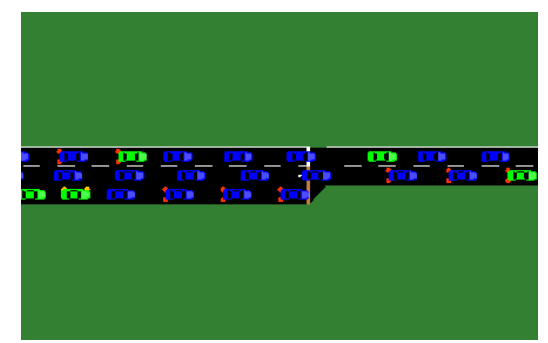

Figura 1. Captura de tela da execução do simulador SUMO demonstrando o afunilamento causado pela invasão do acostamento.

Por aparentar ser prejudicial ao trânsito, torna-se interessante um estudo para quantificar o impacto da invasão do acostamento no tráfego de veículos. Esta investigação é realizada a seguir.

\section{Simulação de Vias Sintéticas}

O simulador escolhido para quantificar o impacto das ações no trânsito e qualificá-las é o SUMO [Lopez et al., 2018]. Esse é um software livre que permite simular o comportamento microscópico de tipos de veículos variados em uma dada rede de vias. O SUMO é muito utilizado na literatura como gerador de mobilidade para alimentar um simulador de redes veiculares. Para simular o trânsito de veículos em uma rodovia, é possível combinar diferentes parâmetros de diferentes modelos de mobilidade, que definem como veículos se comportam quando seguem outros veículos (Car Following Models), assim como modelos matemáticos que definem quando um veículo troca de faixa (Lane-Changing Models). Através da combinação destes, pode-se criar classes únicas de veículos, ou seja, definir o modelo de mobilidade de cada veículo de acordo com um modelo de comportamento do seu condutor.

\subsection{Simulação}

Para simular um cenário representativo da ação de invasão de acostamento e assim avaliar o seu impacto, foi desenvolvida uma rede de vias sintéticas utilizando o editor gráfico de redes do SUMO, o NETEDIT. Como o problema trazido pela invasão do acostamento é análogo a um afunilamento de vias, e como no SUMO não existe o conceito de acostamento, a rede desenvolvida para a simulação tem como característica principal a diminuição do número de faixas, sendo uma delas a representação do acostamento.

Uma rede de vias no SUMO é composta por nós e enlaces. Os enlaces são vias com número de faixas e comprimento configuráveis e têm como função ligar um nó ao 
outro. Um nó é tratado como uma interseção e serve para traçar as rotas dos veículos gerados pela simulação. A rede desenvolvida é mostrada na Figura 2. O primeiro enlace tem duas faixas de $200 \mathrm{~m}$. O segundo possui 3 faixas, $1.000 \mathrm{~m}$ de comprimento e é o enlace alvo de estudo - de onde retiram-se as estatísticas apresentadas mais à frente pois o afunilamento acontece em seu fim, na fronteira com o terceiro enlace da rede. Este possui $100 \mathrm{~m}$ e 2 faixas, uma a menos do que o anterior. Entre o terceiro e o quarto enlace - que também tem comprimento de $100 \mathrm{~m}$ e 2 faixas - existe uma parada obrigatória. Essa parada foi colocada para atuar como o mecanismo gerador de congestionamento. Assim, pode-se analisar os problemas do mal comportamento do motorista em uma via congestionada, imitando o cenário real.

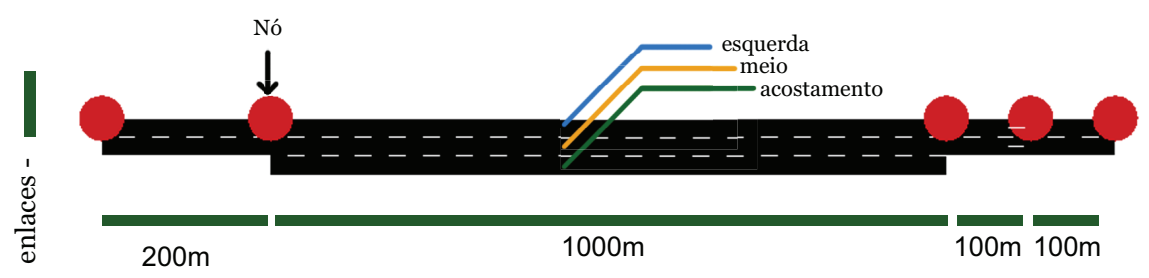

Figura 2. Rede desenvolvida para a simulação no SUMO.

Quanto aos veículos, são definidas duas classes de carros neste trabalho. Ambas são construídas baseando-se nos modelos padrões do SUMO de troca de faixas LC2013 [Erdmann, 2015], que permite variar a cooperação e o comportamento no trânsito de motoristas e o modelo de seguimento de veículos carFollowing-Krauss, que leva os condutores à maior velocidade possível enquanto mantém uma distância segura dos outros veículos [Lopez et al., 2018]. A primeira, denominada motorista regular, é composta por condutores que seguem as regulações de trânsito, se mantendo nas duas faixas originais. Já a segunda, denominada motorista infrator, é composta por motoristas que podem invadir o acostamento (ou a faixa adicional), mas não necessariamente o farão. O motorista infrator simula o condutor que transita pelas faixas regulares mas que pode, eventualmente, invadir o acostamento. A decisão única de cada veículo dessa classe de cometer essa infração varia de acordo com a situação do trânsito e o determinado pelo modelo de mudança de faixa.

A quantidade de tráfego no SUMO pode ser controlada através da probabilidade de um veículo ser emitido a cada segundo. Com a finalidade de garantir tráfego suficiente para gerar congestionamento a partir de determinado momento, fixou-se essa probabilidade em $90 \%$. No conjunto do tráfego gerado, é possível variar a quantidade de veículos das duas classes de forma a medir o impacto que os motoristas infratores realmente têm sobre o trânsito. Para isso, a probabilidade de um motorista regular (MR) e de um motorista infrator (MI) serem emitidos segue a igualdade:

$$
(M R * M I)+M R *(1-M I)+M I *(1-M R)=0,9 .
$$

Desde que a probabilidade de geração de veículos seja grande o suficiente para gerar um congestionamento total das vias, o comportamento observado entre as simulações deve ser o mesmo a partir desse momento. A variação da probabilidade influencia apenas no momento em que o congestionamento total acontece. Dessa forma, foram realizadas 
Tabela 1. Diferentes proporções entre motoristas regulares (MR) e motoristas infratores (MI) utilizadas nas simulações.

\begin{tabular}{|c|c|c|}
\hline Configuração & Fração de MR & Fração de MI \\
\hline 1 & 0,900 & 0,000 \\
\hline 2 & 0,880 & 0,166 \\
\hline 3 & 0,860 & 0,285 \\
\hline 4 & 0,840 & 0,375 \\
\hline 5 & 0,820 & 0,444 \\
\hline 6 & 0,800 & 0,500 \\
\hline 7 & 0,700 & 0,667 \\
\hline
\end{tabular}

dez rodadas de simulação com sete diferentes configurações de MR e MI. Cada experimento de simulação dura 50.000 segundos, aproximadamente 13,9 horas. A primeira com nenhum motorista infrator e a sétima com o maior MI, de 0,667. As variações de MI e de MR seguem conforme a Tabela 1. Os gráficos gerados contém as barras de desvio padrão que, por conta de seus tamanhos, não são visíveis.

\subsection{Resultados}

A Figura 3(a) ilustra o aumento do congestionamento por faixa, na medida em que uma porção maior dos veículos invade o acostamento. O eixo Y representa o tempo médio perdido por veículo no trânsito, em segundos, para cada uma das faixas simuladas. Esse é dado pela diferença entre o tempo que um veículo leva para completar a sua rota na rede vazia e o tempo que ele leva para completá-la no presente cenário avaliado na simulação. No eixo X, é variada a fração de motoristas da simulação que, de fato, invadiu o acostamento. Esta fração foi levada até $24 \%$ neste gráfico. Deve-se notar que quando a fração dos veículos que invadem o acostamento se aproxima e, depois, passa de 33\%, o tempo gasto ao trafegar pelo acostamento é maior ou igual ao tempo gasto trafegando por uma das faixas regulares. Assim, isto significa que o motorista infrator deixa de ter uma recompensa ao invadir o acostamento. Isso acontece porque, com apenas três faixas (duas regulares e uma do acostamento), se um terço dos motoristas adentram o acostamento, ele é tão populado quanto as outras faixas. Como consequência, na vida real, a porcentagem de motoristas que aderem à prática é bem menor que $24 \%$. Levou-se a proporção até este ponto por não ter sido possível a obtenção da estatística real de quantos motoristas desrespeitam a regra.

É interessante notar na Figura 3(a) que, com 15\% dos veículos infratores, o tempo médio perdido por motorista na faixa do meio aumentou em aproximadamente $(60 \pm$ $1,2) \%$. Com $8 \%$ de infratores, o aumento do tempo gasto pelos veículos na faixa do meio já é de $(17 \pm 0,7) \%$, aproximadamente. Esse grande impacto sobre a faixa do meio, que já é expressivo mesmo em frações menores de infratores, acontece porque o motorista no acostamento, quando muda para as faixas regulares, muda diretamente para essa faixa, provocando a frenagem por parte de seus condutores. Esse fato explica, também, o comportamento da curva que representa a faixa esquerda.

O mesmo efeito é ilustrado pela Figura 3(b), porém demonstrando outra dimensão: o tamanho do congestionamento produzido. O eixo Y representa a soma dos comprimentos de trechos congestionados que foram observados ao longo das simulações, que são os comprimentos medidos em termo do número de veículos que se encontram no congestio- 


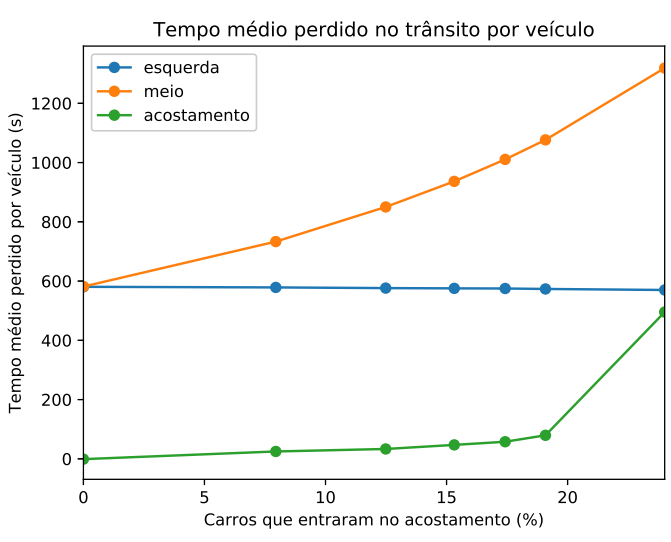

(a) Tempo perdido no trânsito.

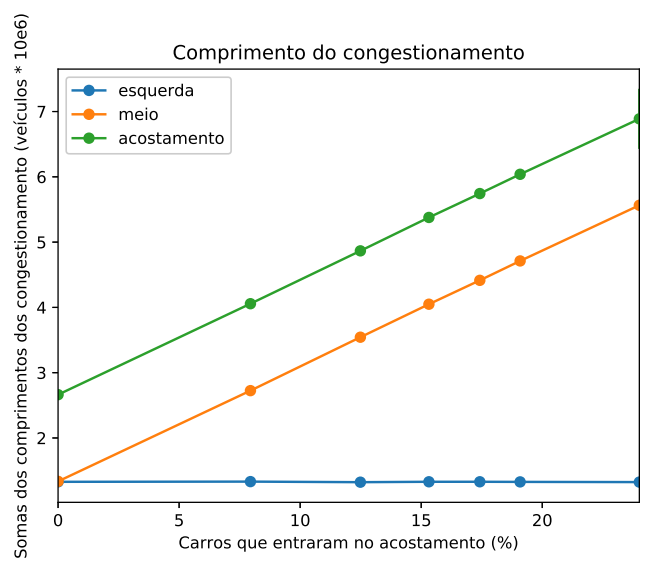

(b) Soma dos comprimento dos congestionamentos por faixa ( ${ }^{\circ}$ de veículos).

Figura 3. Tempo perdido no trânsito e comprimento dos congestionamentos gerados em função do percentual de invasão do acostamento.

namento: o tamanho da fila.

Esta medida é produzida pelo SUMO para cada faixa de rolamento. Um veículo é considerado parte de um congestionamento se tem a sua velocidade reduzida a $0,1 \mathrm{~m} / \mathrm{s}$ ou menos. O eixo X é o mesmo da Figura 3(a), representando a fração de motoristas que invadiu o acostamento na simulação. O congestionamento na faixa do meio aumenta de forma significativa: com 5\% dos veículos infratores, a soma dos congestionamentos aumentou em $(66 \pm 2,7) \%$ se comparada a $0 \%$ de infratores. Com $8 \%$ de motoristas invadindo o acostamento, o aumento na quantidade de veículos em fila, considerando a soma das três faixas, foi de $(67 \pm 1,4) \%$ aproximadamente. Pode-se assim observar outro impacto substancial desta ação negativa por parte dos motoristas.

Ocorre que, não havendo mudanças de faixa, o congestionamento na simulação é causado somente pela parada obrigatória, no terceiro enlace, mecanismo utilizado para gerar o congestionamento inicialmente. Com o maior número de infratores, as mudanças da faixa do acostamento para a faixa do meio tornam-se mais frequentes, ocasionando a frenagem por parte dos condutores da faixa de destino. A partir de, aproximadamente, $22 \%$ de infratores, o tamanho do congestionamento na faixa de acostamento supera a da faixa esquerda. Como esta faixa não sofre com a entrada de outros veículos no modelo de mobilidade do SUMO, sua fluidez se mantém praticamente constante. O acostamento, por outro lado, por mais que ocupado por uma quantidade menor de veículos, demonstra esse comportamento pois o condutor, ao chegar ao final da faixa, é obrigado a reduzir a sua velocidade até completar a mudança para a faixa do meio, propagando a sua desaceleração para os motoristas atrás dele.

O impacto negativo causado pelos infratores sobre a rede de tráfego também tem consequências ambientais. A Figura 4(a) mostra a quantidade média de $\mathrm{CO}_{2}$ (gás carbônico) emitida por veículo da simulação (eixo Y) em função da porcentagem de carros que invadiram o acostamento (eixo $\mathrm{X}$ ). A curva dessa figura é muito próxima à da Figura 4(b), que registra o consumo de combustível médio por automóvel da simulação (eixo $\mathrm{Y}$ ) em função do mesmo eixo $\mathrm{X}$. Isso porque a emissão de $\mathrm{CO}_{2}$, assim como a 
de outros poluentes, é proporcional ao consumo de combustível. Com $15 \%$ de infratores, a emissão de $\mathrm{CO}_{2}$ e o consumo de combustível aumentaram, respectivamente, em $(26 \pm 0,8) \%$ e $(25 \pm 0,5) \%$. Com apenas $8 \%$ de infratores, o aumento da produção de $\mathrm{CO}_{2}$ já é de aproximadamente $(15 \pm 0,4) \%$.

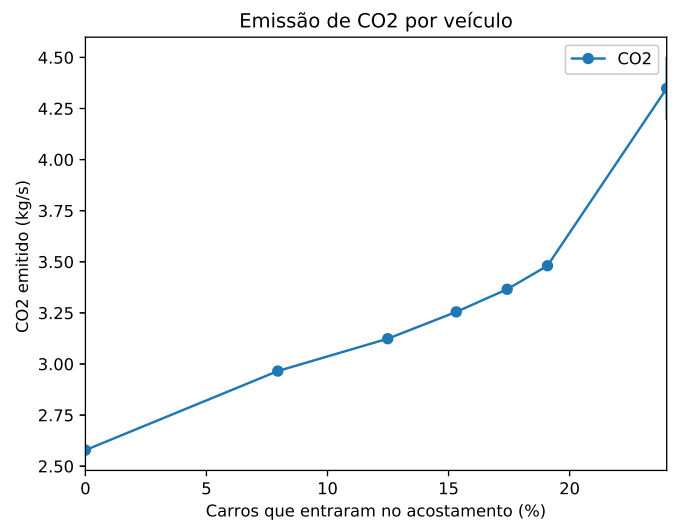

(a) Emissão de $\mathrm{CO}_{2}$.

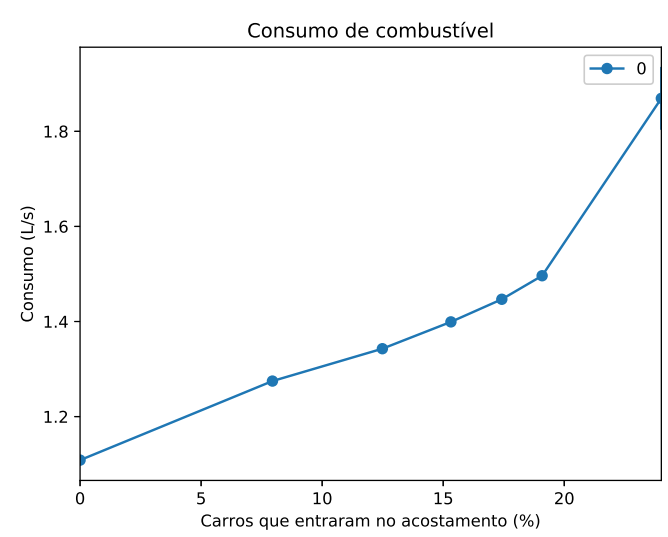

(b) Consumo de combustível.

\section{Figura 4. Emissão de $\mathrm{CO}_{2}$ e consumo de combustível por veículo em função do percentual de invasão do acostamento.}

\section{Simulação de Vias Reais}

Nesta seção, para complementar a análise realizada anteriormente em um cenário completamente controlado, constrói-se um cenário de simulação com parâmetros obtidos de uma rodovia real. O objetivo desta simulação é confirmar a dimensão do impacto do comportamento do motorista em uma situação real.

\subsection{Simulação}

Para a simulação com dados de trânsito reais, foram coletados dados do governo britânico, publicado pelo serviço NTIS (National Traffic Information Services) da Highways England [HighWays England, 2020]. Os dados, coletados a cada quinze minutos por uma unidade de monitoramento de trânsito, dizem respeito ao período entre 5:59 e 11:59 do dia seis de fevereiro de 2019. O trecho analisado é uma seção da rodovia A1, sentido sul. O trecho contém duas faixas, como ilustra a Figura 5, e tem comprimento de $758 \mathrm{~m}$, aproximadamente.

Com uma pequena formatação nos dados e com a ajuda do software do SUMO, OD2TRIPS [Lopez et al., 2018], que cria um arquivo de rotas a partir de uma matriz de origens e de destinos de veículos, foi gerado um arquivo reconhecido pelo SUMO com as informações dos veículos. Para a simulação, duas redes foram consideradas. A primeira, sem acostamento, composta por um único enlace de duas faixas e de $758 \mathrm{~m}$ de comprimento. A segunda, com acostamento, dividida em três enlaces para adicionar uma faixa extra ao segundo, representando o acostamento. Os comprimentos dos enlaces um, dois e três são, respectivamente, 100 m, $558 \mathrm{~m}$ e $100 \mathrm{~m}$.

Na simulação com acostamento não foi controlado o número de motoristas que o invadem. A faixa extra foi tratada como uma faixa comum, seguindo a lógica de redução do problema da invasão do acostamento ao problema de afunilamento de uma via. 


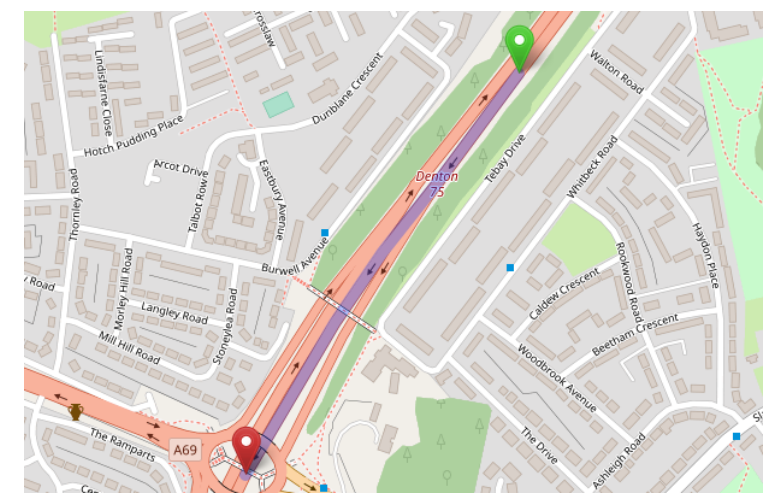

Figura $5 . \quad$ Captura do trecho simulado no OpenStreet-
Maps [OpenStreetMap contributors, 2017].

\subsection{Resultados}

Dos dados, as velocidades médias dos veículos $(89,25 \mathrm{~km} / \mathrm{h}$, em média), indicavam um trânsito fluido na seção da rodovia estudada. Por isso, o esperado é que, para a simulação sem acostamento, não haja formação de congestionamento. Essa simulação é análoga à simulação de número 0 da Tabela 1 , com exceção da existência do mecanismo para gerar congestionamento: a parada obrigatória no penúltimo nó.

Conforme a Tabela 2, a simulação sem acostamento teve o seu trânsito fluido, acumulando, em todas as faixas, um tempo perdido de apenas $(5,54 \pm 0,56) \mathrm{s}$ por veículo. Esse valor é aproximadamente 25 vezes menor do que o tempo perdido por veículo na simulação com o acostamento, que chega a $(137,95 \pm 0,56)$ s. Como na simulação de vias sintéticas, a via mais afetada pela faixa adicional é a do meio, apresentando um tempo perdido no trânsito por veículo 22 vezes maior do que na simulação sem acostamento. Isso acontece porque os veículos mesclando do acostamento para essa faixa, quando chegam ao final do acostamento ou a uma velocidade baixa, forçam a frenagem por parte dos veículos da faixa do meio.

Tabela 2. Tempo perdido por veículo nas simulações, por faixa.

\begin{tabular}{|c|c|c|}
\hline Faixa/Simulação & Sem Acostamento (s) & Com Acostamento (s) \\
\hline Esquerda & $2,62 \pm 0,04$ & $2,62 \pm 0,05$ \\
\hline Meio & $2,92 \pm 0,02$ & $63,93 \pm 0,48$ \\
\hline Acostamento & $\mathrm{X}$ & $71,40 \pm 0,29$ \\
\hline
\end{tabular}

A Tabela 3 ratifica os resultados ilustrados pela Tabela 2. Praticamente não há congestionamento na simulação sem acostamento. Os congestionamento de comprimento 0,00 e $(0,4 \pm 0,8)$ veículo nas faixas do meio e esquerda são resultantes de uma média de simulações. Por outro lado, na simulação com acostamento, houve um aumento expressivo na soma dos comprimentos dos congestionamentos nas faixas do meio e do acostamento. Isso acontece pelo mesmo motivo que gerou dados maiores de tempo perdido nessas mesmas faixas.

Sobre a emissão de $\mathrm{CO}_{2}$, a simulação com acostamento gerou uma emissão aproximadamente 2,6 vezes maior do que a gerada na simulação sem acostamento. Enquanto na simulação sem acostamento emitiu-se $(280,0 \pm 0,5) \mathrm{g} / \mathrm{s}$ de $\mathrm{CO}_{2}$, na outra emitiu-se $(720,0 \pm 1,6) \mathrm{g} / \mathrm{s}$. 
Tabela 3. Soma dos comprimentos dos congestionamentos por faixa.

\begin{tabular}{|c|c|c|}
\hline Faixa/Simulação & Sem Acostamento (veículos) & Com Acostamento (veículos) \\
\hline Esquerda & $0,40 \pm 0,80$ & $0,40 \pm 0,49$ \\
\hline Meio & 0,00 & $55166.80 \pm 319,66$ \\
\hline Acostamento & $\mathrm{X}$ & $58010.00 \pm 624,82$ \\
\hline
\end{tabular}

\section{Prevenção e Mitigação de Ações Negativas}

Como demonstrado na literatura para ações negativas do motorista em geral e, neste trabalho, para a invasão de acostamento, o impacto do motorista mal comportado na fluidez do trânsito é significativo. Assim, deve-se buscar formas de prevenir ou reduzir o efeito destas ações negativas. Para tentar evitá-las, o condutor precisa ser avisado de sua ação negativa. Além disso, ele pode receber uma penalidade quando a fizer, um incentivo quando evitá-la, ou até mesmo ser impedido de fazê-la, dependendo de qual a ação. A comunicação entre veículos possibilita a identificação dessas ações, o aviso ao condutor $\mathrm{e}$, até mesmo, a operação de veículos autônomos e dos munidos de CACC (Cooperative Adaptive Cruise Control) [Bevly et al., 2016].

Para aplicações que requerem uma localização geográfica dos veículos com precisão suficiente para discernir a faixa em que eles se encontram, uma solução é a utilização da tecnologia GPS RTK (Real Time Kinematic). Essa precisão consegue ser atingida combinando medidas de uma estação estática, cujas coordenadas são conhecidas, com medições de GPS [Bevly et al., 2016].

Outras tecnologias também podem ser utilizadas para estabelecer a comunicação entre veículos. Como exemplo, tem-se a tecnologia LoRa (Long Range). Embora tenha sido desenvolvida para a comunicação direta entre nó e gateway, alguns autores propõem a integração da rede LoRa com o conceito de redes veiculares ad-hoc, utilizando-a para apoiar a configuração das conexões V2V e V2I [Sanchez-Iborra et al., 2017].

\subsection{Mitigação do Problema da Invasão do Acostamento}

Como o problema da invasão do acostamento pode ser reduzido ao problema gerado pelo afunilamento de uma via, é interessante entender a atitude ideal a ser tomada para diminuir suas consequências no tráfego de veículos. Se existe um final para uma das faixas, obrigando a mudança dos condutores para a faixa mais próxima, o veículo da faixa de origem deve manter uma distância segura entre os dois veículos da faixa de destino para poder fazer uma mudança sem maiores complicações. Surge, no entanto, um problema: se não há espaço suficiente entre os veículos da faixa de destino, o veículo é obrigado a parar, gerando congestionamento na faixa de origem e, eventualmente, também na faixa de destino, quando obrigar a frenagem dos condutores desta última [Bevly et al., 2016].

Se as distâncias entre os veículos da faixa de destino forem suficientemente grandes, o veículo da faixa de origem pode efetuar a mudança sem a frenagem de qualquer condutor à sua volta, evitando a formação de congestionamento. Utilizando a comunicação entre veículos, é possível coordenar essa mesclagem a partir de dados de localização e de velocidade dos automóveis da região em tempo real. Existem algumas propostas de algoritmos de mesclagem de faixas na literatura [Wang et al., 2009, Baselt et al., 2014]. Esses algoritmos não impedem a invasão do acostamento, mas visam mitigar os efeitos negativos resultantes da mesclagem de faixa. Dentre eles, o Zíper. A 
ideia básica da mudança Zíper é que os veículos da faixa de origem ocupem cada espaço entre os veículos da faixa de destino. Dessa forma, um condutor da mesclagem resultante sempre terá em sua frente um motorista de faixa inicial diferente, como ilustra a Figura 6.

Em [Baselt et al., 2014] é apresentado o conceito de mudança justa, que mede o tempo esperado pelos veículos no congestionamento até o ponto de mesclagem (obstrução), e avalia a mesclagem Zíper. Essa torna-se justa para as duas faixas se a sua prática começar a ser realizada antes da formação do congestionamento das vias.

Um algoritmo de mesclagem de faixa só seria completamente eficaz se realizado inteiramente de maneira automática. No entanto, com a comunicação entre veículos, é possível auxiliar o condutor a tomar as decisões corretas segundo os algoritmos, possivelmente mitigando os efeitos negativos da invasão do acostamento.

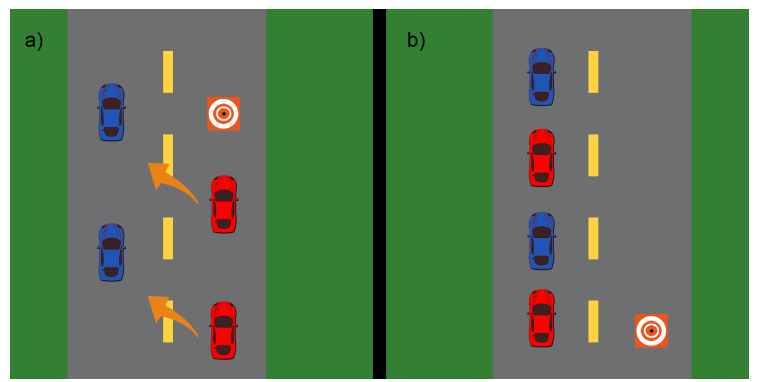

Figura 6. Os veículos vermelhos, obrigados a mesclarem com a faixa esquerda por conta da obstrução (a), mudam para esta faixa no modo Zíper (b).

\subsection{Penalidade \& Incentivo}

Normalmente, para punir infrações de trânsito, os órgãos governamentais aplicam uma multa ao infrator. Esse mecanismo tem a intenção de diminuir os índices de acidentes, ou seja, diminuir a prática de ações consideradas ruins por esses órgãos. A sua eficiência é, em média, a maior dos mecanismos de controle: condutores que acumulam pontos e correm riscos de perder a sua licença tendem a ter mais cuidado no trânsito [Pinquet et al., 2011].

Por outro lado, o incentivo para que o condutor não realize a má prática também é eficaz, como o pagamento de uma certa quantia para condutores que optam por se deslocar em momentos fora do horário de pico [Merugu et al., 2009]. Uma possível redução no valor dos impostos sobre o veículo para quem não pratica ações consideradas prejudiciais ao trânsito também é um exemplo disso. Por isso, é interessante aplicar tanto incentivos quanto penalidades para reduzir ao máximo ações prejudiciais à fluidez do trânsito.

A fiscalização de ações negativas por câmeras e agentes de trânsito tem um limite de cobertura. Se a comunicação entre veículos for introduzida, torna-se mais fácil a fiscalização. Isso porque o processo de atribuição de penalidade/incentivo pode ser feito de forma automática a partir dos dados de geolocalização, velocidade e aceleração de cada veículo, em tempo real. O trabalho de [Abbas et al., 2019] propõe um sistema de multas por excesso de velocidade automáticas, enviando uma mensagem prévia aos motoristas por meio de redes veiculares. Essa mensagem notifica o condutor de sua infração e indica que, se a sua velocidade não se regularizar dentro de um intervalo de tempo, a multa (penalidade) será aplicada. Entende-se que o motorista tende a reduzir sua velocidade 
frente à possibilidade de uma penalização. Além disso, outras formas de incentivo podem ser estabelecidas com a ajuda de VANETs. No caso do acostamento, por exemplo, por meio de mensagens de aviso, os condutores podem ser informados sobre o tempo adicional que causariam aos outros motoristas da região no caso de invadirem o acostamento, desencorajando a invasão.

Uma outra proposta, apresentada em [Chang et al., 2015], propõe incentivar usuários de telefones inteligentes a reportarem infrações. O usuário anexa uma prova da ação negativa e se, depois da análise, confirmar-se uma infração, esse recebe um valor como recompensa. Essa ideia pode ser estendida para condutores cujos veículos possuem sensores de movimento, como os munidos de ACC (Adaptive Cruise Control) e de câmeras. Dessa forma, sabendo da existência desse sistema, o condutor pode ser desencorajado a praticar as ações negativas.

\section{Conclusões}

Neste trabalho, foi estudado o conceito de ações prejudiciais ao trânsito e escolhida para análise a invasão do acostamento, um problema frequente nas rodovias brasileiras. Por meio de simulações efetuadas no simulador de mobilidade urbana SUMO, pôde-se constatar que a invasão ao acostamento, que é análoga ao afunilamento de faixas em uma via, é muito prejudicial ao trânsito e ao meio ambiente.

De acordo com os resultados da simulação sintética, os motoristas da faixa mais próxima ao acostamento perdem $(60 \pm 1,2) \%$ de tempo no trânsito quando $15 \%$ dos motoristas cometem a infração. Além disso, com essa mesma proporção de infratores, o consumo de combustível e a emissão de gás carbônico cresce $(26 \pm 0,8) \%$ e $(25 \pm$ $0,5) \%$, respectivamente. As simulações baseadas em dados de trânsito reais mostram um aumento de 25 vezes de tempo perdido no trânsito quando motoristas praticam essa ação, se comparado à simulação sem infratores, de trânsito livre. A emissão de $\mathrm{CO}_{2}$ mostrou-se, nesse mesmo contexto, 2,6 vezes maior.

Há, no entanto, propostas de soluções e tecnologias promissoras para a mitigação ou prevenção de ações ruins para o trânsito. Neste contexto, deu-se maior enfoque no artigo ao problema da invasão do acostamento. Com a comunicação de veículos, é possível executar algoritmos de mesclagem de faixa, como o Zíper, para mitigar os efeitos resultantes dessa ação negativa. Além disso, o trabalho identificou mecanismos de incentivo/penalidade ao motorista que pratica esse tipo de ação, que serão objeto de investigações futuras nesta linha de pesquisa.

Futuramente, pretende-se avaliar, por meio de simulações de redes veiculares utilizando o padrão IEEE 802.11p, a viabilidade de mecanismos de mesclagem de faixa, considerando métricas de rede e os requerimentos mínimos para o pleno funcionamento de um algoritmo para este fim.

\section{Agradecimentos}

O presente trabalho foi realizado com apoio da Coordenação de Aperfeiçoamento de Pessoal de Nível Superior Brasil (CAPES) - Código de Financiamento 001. Também foi parcialmente financiado pelo CNPq, FAPERJ e pelo processo $n^{0} 15 / 24494-8$ da Fundação de Amparo à Pesquisa do Estado de São Paulo (FAPESP). 


\section{Referências}

Abbas, M. K., Low, T. J. e Abdulla, R. (2019). Automated fining system for high speed driving offences via VANET. Em International Conference on Green and Human Information Technology (ICGHIT).

Baselt, D., Knorr, F., Scheuermann, B., Schreckenberg, M. e Mauve, M. (2014). Merging lanes - fairness through communication. Vehicular Communications, 1(2):97-104.

Bevly, D., Cao, X., Gordon, M., Ozbilgin, G., Kari, D., Nelson, B. e Ozguner, U. (2016). Lane change and merge maneuvers for connected and automated vehicles: A survey. IEEE Transactions on Intelligent Vehicles, 1(1):105-120.

Chacon, S. e Kornhauser, A. (2012). The effect of augmented driver behavior on freeway traffic flow. Em Annual Transportation Research Forum (TRF2012), volume 2, p. 1215-1244.

Chang, S., Ren, W. e Nahrstedt, K. (2015). Dynamic incentive mechanism for traffic surveillance. Em IEEE Globecom Workshops (GC Wkshps), p. 1-6.

Chaurasia, B. K. e Verma, S. (2009). Haste induced behavior and VANET communication. Em IEEE International Conference on Vehicular Electronics and Safety (ICVES), p. 19-24.

Erdmann, J. (2015). SUMO's lane-changing model. Lecture Notes in Mobility.

HighWays England (2020). National traffic information services. https://data . gov.uk/.

Lopez, P. A., Behrisch, M., Bieker-Walz, L., Erdmann, J., Flötteröd, Y.-P., Hilbrich, R., Lücken, L., Rummel, J., Wagner, P. e Wießner, E. (2018). Microscopic traffic simulation using SUMO. Em IEEE Intelligent Transportation Systems Conference (ITSC).

Malta, L., Miyajima, C. e Takeda, K. (2009). A study of driver behavior under potential threats in vehicle traffic. IEEE Transactions on Intelligent Transportation Systems, $10: 201-210$.

Merugu, D., Prabhakar, B. e Rama, N. (2009). An incentive mechanism for decongesting the roads: A pilot program in bangalore. Em NetEcon, ACM Workshop on the Economics of Networked Systems.

OpenStreetMap contributors (2017). Planet dump retrieved from https://planet.osm.org . https: / / www. openstreetmap.org.

Pinquet, J., Dionne, G., Vanasse, C. e Mathieu, M. (2011). Incentive mechanisms for safe driving: A comparative analysis with dynamic data. Review of Economics and Statistics, Massachusetts Institute of Technology Press (MIT Press).

Sanchez-Iborra, R., Sanchez-Gomez, J., Santa, J., Fernandez, P. e Skarmeta, A. (2017). Integrating lp-wan communications within the vehicular ecosystem. Journal of Internet Services and Information Security, 7:45-56.

Wang, Z., Kulik, L. e Ramamohanarao, K. (2009). Robust traffic merging strategies for sensor-enabled cars using time geography. Em ACM SIGSPATIAL International Conference on Advances in Geographic Information Systems, p. 362-371. 